\title{
A system dynamics model for behavioral analysis of safety conditions in a chemical storage unit
}

\author{
Hafida Bouloiz $^{\mathrm{a}}$, Emmanuel Garbolino ${ }^{\mathrm{b} *}$, Mohamed Tkiouat ${ }^{\mathrm{a}}$, Franck Guarnieri ${ }^{\mathrm{b}}$ \\ ${ }^{a}$ Industrial Engineering Department, Engineers' Mohammadia School, Avenue Ibn Sina- BP \\ 765, Agdal, Rabat, Morocco \\ bouloizhafida@yahoo.fr; tkiouat@emi.ac.ma \\ ${ }^{\mathrm{b}}$ Crisis and Risk Research Centre, Mines ParisTech, 1 Rue Claude Daunesse, BP 06904 \\ Sophia Antipolis, Cedex, France \\ emmanuel.garbolino@mines-paristech.fr; franck.guarnieri@mines-paristech.fr
}

\begin{abstract}
This paper aims to develop a system dynamics model in order to formalize causal interdependencies between safety factors (technical, organizational and human). These factors define safety conditions in a complex industrial system. It is a systemic approach founded on the method of system dynamics and the case study is a storage unit for chemical products located in Morocco. System dynamics using VENSIM® software has been applied to assess the safety of the storage unit by modeling the activity of the industrial system. Through simulation, users can define deviant scenarios in order to improve safety of the industrial system and implement managerial tools involving organizational, technical and human factors.
\end{abstract}

Keywords: system dynamics, safety, organization, causal interaction, system behavior, scenarios.

* Corresponding author. Tel.: +33 (0) 4.93.95.74.75. Fax: +33 (0) 4.93.95.75.81

E-mail address: emmanuel.garbolino@mines-paristech.fr (E. Garbolino). 


\section{Introduction}

The complexity of industrial systems poses a challenge for industrial safety as it can be a source of deviations from normal behavior. These deviations are the cause of incidents or accidents. Complexity is a source of unpredictable system behavior because of the causal interactions between its different elements (technical, human, organizational).

There are many examples of accidents such as Bhopal (1984), Piper Alpha (1988) and Chernobyl (1986), which demonstrate the role played by technical, human and also organizational factors in these catastrophic events (Jasanoff, 1994; Paté-Cornell, 1999; Salge \& Milling, 2006). The lessons learned from these accidents show the complexity of industrial systems that are composed, in reality, of a set of elements. The nature of the relations between these elements gives the system a certain level of unpredictable behavior over time (Reason, 1997; Perrow, 1994; Roberts, 1990).

The field of industrial risk has evolved in terms of risk analysis methods. Methods have traditionally focused primarily on the technical dimension. They describe accidents using a sequential model which represents the linear succession of a set of events linked by cause and effect. Among these sequential models, HAZOP (Hazard and Operability Study; Rogers, 2000), FMEA (Failure Mode Effect Analysis; Nicolet-Monnier, 1996), FTA (Fault Tree Analysis; Khan \& Abbasi, 1998), FMECA (Failure Mode Effect Criticality Analysis; Rogers, 2000), and PRA (Preliminary Risks Analysis; Nicolet-Monnier, 1996; Rogers, 2000) are the risk analysis models most often seen in safety reports applied to the industrial context.

These sequential models do not take into account interactions between system components and do not adequately address human and organizational factors. These models are based on event chain accident approach. Therefore, the traditional methods of risk analysis are not appropriate for complex systems, because the interactions between different components of the system are not considered in these methods. Weaknesses and limitations of the sequential model are detailed in Leveson (2004).

More recently, new methods have been developed which take into account the human and organizational dimension. These methods, known as organizational methods, define an accident as the result of the presence of several failure factors. These methods include: TRIPOD (Groeneweg, Lancioni, \& Metaal, 2002), SAM (System-Action-Management; PatéCornell and Murphy, 1996), ATHOS (Technical Analysis, Human and Organizational Security; Le Coze, Vince, Salvi, Prats, \& Plot, 2002), and CREAM (Cognitive Reliability and Error Analysis Method; Hollnagel, 1998). These methods discuss the organizational factors which influence the action and conduct of humans and the equipment operation. They make it possible to highlight the influence of the organizational environment on technical and human factors. But these organizational methods present only a static model of a system. They do not allow the formalization of dynamic interactions between system components and do not take into account feedback effects (Garbolino et al., 2009). They are therefore insufficient to understand the dynamic complexity of the system. 
Systems are not static (Leveson, 2004); they change over time in unpredictable ways. The dynamic behavior of the system can be understood by considering it as complex and open, with many interactions. Therefore, the accident is a phenomenon emerging from the interactions within the system (Leveson, 2004; Hollnagel, 2004), and not a sequence of events linked by cause and effect as shown by sequential models of risk analysis.

This paper aims to formalize the dynamic interactions between system components that are human, technical and organizational, and to take into account feedback effects of these components in the modeling of safety conditions in a complex industrial system. The finality is to provide a tool for decision support that allows controlling of safety in a context characterized by a diversity of decision levels. A system dynamics has been adopted to construct a dynamic model of safety conditions.

The adaptation of system dynamics to industrial safety can show that the accident is also a phenomenon emerging from the interactions within the system and not only a sequence of events linked by cause and effect.

The methodology used to construct the model has been described by Garbolino et al. (2009, 2010a and 2010b). This methodology is characterized by four main steps (Figure 1):

a) Model building and system behavior simulation: this step involves

a. the choice of variables that continuously describe the state of the interactions between system components;

b. the definition of the assumptions that establish these interactions in order to formalize the proposed system;

c. the development of a causal model of the relations between the variables, and

d. the modeling of the relations using differential equations and implementing them in the VENSIM $®$ software.

b) Dynamic risk analysis with risk assessment methods: this is based on a very well defined method. It allows identification of all possible failures and, using the dynamic model, study of the eventual variations in system behavior.

c) Consequences simulation of all kinds of failure: this step involves simulating dangerous phenomena (toxic atmospheric releases, overpressures, heat flux etc.) and estimating the impact on infrastructure and the population (workers, residents etc.).

d) Dynamic testing of prevention and protection measures to assess their efficiency: this step consists of measuring the efficiency of prevention and protection measures implemented at the plant. It facilitates the definition of new safety measures if necessary. This being the case there is a need to return to the model design step in order to implement the new prevention and protection measures and to simulate their integration.

Figure 1: Description of the dynamic risk analysis methodology (Garbolino et al., 2009, 2010a and 2010b). 
This paper presents a new version of the earlier one which was proposed for the risk analysis. This version addresses the human factors in detail, the organizational factors and also the technical factors: the integration of these three dimensions in the risk management process and the simulation of such socio-technical system are particularly innovative.

There are few works that try to take into account these three dimensions in a dynamic way. In the (Kalantarnia et al. 2009), the authors present a method for dynamic safety management which is founded on Bayesian Theory to update the likelihood of the event occurrence and also probability of the safety system. This method involves essentially technical aspect of risk.

The objective of this paper is to develop a model to which we apply the scenarios tested by computer. The aim is not to make a mathematical model but use a soft transparent for de system dynamics. System dynamics has been applied to understand the structure of storage unit and to represent the interactions between the different variables of the system. The laws of evolution of each variable take into account the values of the variables that influence it and to which they receive information. The simulation of the equations over time generates the dynamic behavior of the system; examples in relation to a chemical storage unit are presented in order to illustrate the features of the model.

This paper is organized as follows: section 2 presents the system dynamics method which is used in this study. Section 3 describes the case study (a chemical storage unit). Section 4 defines and presents the proposed dynamic model applied to the case study. In section 4, simulations and the results of the proposed modeling are presented, in order to demonstrate how the dynamic modeling helps to improve the safety of an industrial system. The conclusion underlines the benefits and limits of the approach.

\section{Modeling Method: System Dynamics}

System dynamics is the theory of system structures, a theory that deals with the study of the causal interactions between the components which constitute the structure of a complex system. It is a modeling methodology for understanding and representing complex systems and analyzing their dynamic behavior (Forrester, 1961). It finds its origin in cybernetics, which is the interdisciplinary study of the structure of regulatory systems (Weiner, 1948). System dynamics is a modeling method that allows a system to be represented in terms of feedback. It is founded on the original work of Forrester, who defined it as "the investigation of the information-feedback character of industrial systems and the use of models for the design of improved organizational form and guiding policy" (Forrester, 1961). System dynamics deals with the study of how the behavior of complex system changes over time.

System dynamics has two interesting aspects: systemic study of the concept of feedback and dynamic study of system behavior. It shows how the structure of a feedback system and the loops that it contains are responsible for its dynamic behavior. It is a method that focuses on the interactions between structural components, and behavior that is founded on the concept of feedback (Aracil, 1984). It is a methodology for designing and analyzing a system 
and simulating its behavior. According to Paulré (1992), the syntax of system dynamics is neutral and independent of the field of application.

\subsection{The Forrester model}

Forrester (1961) developed four steps to create a system dynamics model. The first step is the articulation of the problem: defining the purpose of modeling and identifying the entities, interactions and behaviors to highlight. The second step is to describe the causal relationships between these entities, by building the causal (or influence) diagram. Causal diagrams represent major feedback mechanisms, which reinforce (positive feedback loop) or counteract (negative feedback loop) a given change in a system variable (Sterman, 2000). The third step corresponds to the introduction of stock variables and flow in the system by building a stockflow diagram. This diagram (Figure 2) is a quantitative model and introduces the time dimension by considering the rate of change in the level of variables (stock variables and flow) over time. This model consists of three types of element: stock (or level) elements (also called state variables); flow elements; and auxiliary variables and constants (Garcia, 2006).

Figure 2: Schematic of a system dynamics model using the stock, flow and auxiliary variables proposed by Forrester (Forrester, 1961).

The fourth step is to formulate simulation models. The laws that govern the evolution of each variable take into account the values of the variables that influence it and from which it receives information. The equations that simulate the behavior of the system over a period of time, using initial values for state (stock) variables, generate the dynamic behavior of the system. In this way a system dynamics model allows examination of the long-term behavior of complex systems (Rehan et al., 2005).

\subsection{General Applications}

The system dynamics method has been used in a wide variety of applications: in economics (Tauheed and Wray, 2006; Meadows et al., 1972), hospital systems (Koelling and Schwandt, 2005), engineering (Hjorth and Bagheri, 2006) and geography (Provitolo, 2005). The system dynamics method has also been applied to complex managerial problems such as: development of inter-organizational networks (Akkermans, 2001), optimizing the allocation of marketing resources (Graham and Ariza, 2003), management of multiple projects in research and development (Repenning, 2000), the prevention and management of crises in organizations (Rudolph and Repenning, 2002) and innovations in process implementation (Milling, 2002).

In the field of industrial risk, some studies are founded on the principles of system dynamics in order to analyze industrial accidents. For example, the study by Cooke (2002) describes a system for dynamic analysis of the disaster at the Westray mine. It examines the causal system of Westray including the relations that created the conditions leading to the fatal explosion at the mine in 1992. Paté-Cornell et al. (1997) present a model of relationships 
between managerial, organizational and functional factors, using a causal diagram. This diagram is applied to the analysis of the Piper Alpha accident. Leveson et al. (2003) develop a system dynamics model which describes the causal system of the Walkerton Water Contamination Accident. Other studies have focused on analyzing the reliability of technical systems using system dynamics. This is the case in a study by Kyung and Moosung (2004), which uses systems dynamics to analyze the dynamic reliability of a nuclear power plant, and involves evaluating the boundary conditions when operating a nuclear power plant. Garbolino et al. (2009) propose a methodology based on technical dimensions in order to model and simulate the functioning of a chlorine storage and distribution unit.

Therefore, in this paper, we recommend to develop an integrated framework of modeling safety conditions in an industrial system. The novelty of our framework is the possibility to study the interactions of technical, organizational and human aspects of industrial safety.

The purpose is to provide a tool to support decision that allows piloting safety in a context characterized by the diversity of decision levels in relation with human, technical and organizational factors. The proposed model demonstrates how management practices affect safety factors and through simulation, gives users insights into how to improve safety in the system, and provides managerial tools to address organizational, technical and human factors.

\subsection{VENSIM® software: a platform to simulate complex systems}

In this paper, VENSIM ${ }^{\circledR}$ software is applied to system dynamics. VENSIM $®$ is simulation software developed by Ventana Systems which analyses variable relationships and the structural elements of a diagram using a model equation. It is characterized by a visual output; system behavior and system status are shown graphically. It is useful for comparative analysis. The features of the software are outlined in their reference manual (Ventana Systems, 1999).

\section{The Case Study}

The chemical storage unit which is the subject of this case study belongs to a company specialized in the manufacture of chemical substances for industrial use. It is located in the industrial area of Casablanca (Morocco). This company is part of an industrial group which is a global leader in the field of specialized chemicals. The industrial group is active worldwide and has over one hundred companies on five continents. It is organized into the following divisions: chemicals for textile, leather and paper (i.e. polymer dispersions, dyes, acids, and silicones), pigments and additives (i.e. polymer additives, flame retardants, wax) and functional chemical products (i.e. body care products, detergents). The Morocco plant consists of the following units: a storage unit, a manufacturing unit, an analysis laboratory and a maintenance workshop (Figure 3).

Figure 3: Configuration of the industrial site. 
Liquid materials received in bulk are stored in tanks; other bulk materials are stored outside in warehouses identified using common procedures (signs indicating the type of chemical product and instruction labels). The handling of bulk materials outside is done by two means: a forklift and a pallet. Forklifts are used for stacking materials on the shelves and for loading and unloading delivery trucks. Pallets are used to transport materials from one place to another in the plant.

The particular storage unit studied in this paper is the warehouse for flammable materials. The storage temperature for these flammable products should not exceed $35^{\circ}$, as these products can ignite in air and burn continuously. The storage unit is considered as a complex system composed of interacting technical, human and organizational components. The interacting components are:

$\checkmark$ Operators: the operator has responsibility for proper operation of the storage facility.

$\checkmark$ Procedures: constitute supporting information and consist of instructions for product storage, safety data sheets, protection measures in case of an accidental product spill, safety checklists, location sheets, etc.

$\checkmark$ Safety devices: correspond to prevention (alarm, temperature detector) and protection (sprinkler, individual protection kit) equipment.

All these components must be organized in line with the goal of ensuring adequate storage for the products, and avoiding or mitigating any situation that might present a risk.

\section{Proposed Modeling}

In order to better structure the presentation of the dynamic model proposed in this paper, we will follow the steps of the modeling process defined by Forrester (1961). The first step of the modeling process is the articulation of the problem by defining the purpose of modeling and identifying the important entities and interactions. The second step is the development of the causal diagram. The third step is to develop the stock and flow diagram. The fourth step corresponds to the implementation of the model and simulation of its behavior.

\subsection{Articulation of the problem (step 1)}

The purpose of this study is to provide a decision support tool which facilitates risk control management in an environment characterized by diversity of decision levels. These decision levels correspond to human, technical and organizational factors. Once the problem is defined, the variables to be included in the model are identified. As previously mentioned, the purpose of this paper is to formalize the causal interdependencies between safety measures. We propose that risk control is founded on the control of, and interactions between, each component of the industrial system. Control of each component and each interaction means that the component in question must be in a safe state (Bouloiz et al, 2010). Interviews and 
observations were conducted in order to define the level of safety measures at the storage unit in order to draw up an initial causal diagram.

\subsection{Causal diagram (step 2)}

This diagram must show whether the relationship between each pair of variables is positive or negative, that is, if the influence of one variable on another is amplifying (positive influence) or stabilizing (negative influence). Then it is necessary to study the nature of the feedback loops that are formed.

In order to define the interactions related to behavioral factors (motivation, stress, competence, training, work environment), we have relied on existing studies which have examined these factors (Ryan and Deci, 2000; Karsky and Donnadieu, 1990; Giambiasi et al., 2005; Jones, 2005; Boucher and Burlat, 2003; Harvey et al, 2006).

Other variables are more related to the system being studied (the chemical storage unit). In this case, we relied on our field observations and also on the expertise of workers within the company.

The objective is not to detail all the organizational, human variables and their interconnections. Components used are the components that are specific to the studied system. All the variables of the model developed is only the parameters that this system analysis in its approach of risk management. However, among the interests of this model, users can implement other managerial components in order to improve managerial safety of the industrial system. Figure 4 illustrates the causal diagram using VENSIM®.

Figure 4: Causal diagram showing safety conditions in the chemical storage unit.

This causal diagram makes it possible to visualize a set of feedback loops. A favorable work environment has a positive effect on the motivation of operators, and a negative effect on stress (loop B1). Loop B2 shows that the motivation of operators has a positive influence on their safety behavior. Stress has a negative impact on their behavior.

Learning through training increases the competence of operators and has a positive influence on their safety behavior. The relevance of maintenance procedures together with the behavior of operators influences the quality of maintenance, which in turn affects the reliability of the temperature detector and the reliability of the alarm in the warehouse. In this way, the safety behavior of operators defines the quality of monitoring of the storage temperature.

Maintaining the storage temperature in the warehouse (loop B3) depends on the quality of temperature monitoring by operators, the reliability of the temperature detectors and the safety system (a cooling system) activated when the temperature in the storage depot exceeds the prescribed limit of $35^{\circ} \mathrm{C}$. 
Quality of storage safety control is determined by the relevance of checklists and the safety behavior of operators (loop B5). When non-compliant situations are detected, there is a need to analyze them. This both improves safety (loop B6) and has a positive effect on the behavior of operators, who learn and acquire additional knowledge (loop B7). The causal diagram shown in Figure 4 describes the safety conditions in the storage unit and highlights the causal interdependencies between these safety factors.

\subsection{Stock and flow diagram (step 3)}

The flow and stock diagram corresponding to the causal diagram shown in Figure 4 is presented in Figure 5. This figure is a clear demonstration of the relations between the various variables of stock, flow and control.

Figure 5: Stock and flow diagram showing the safety conditions in the chemical storage unit.

Table 1 lists the definition of the variables used to model the safety conditions in the chemical storage unit.

Table 1: Definition and role of all variables used to model the safety conditions in the warehouse for flammables.

\begin{tabular}{|c|c|c|}
\hline Variable Name & Definition & Function \\
\hline $\begin{array}{l}\text { Temperature alarm in the } \\
\text { warehouse for flammables }\end{array}$ & $\begin{array}{l}\text { IF THEN ELSE }\left(\mathrm{T}^{\circ} \text { in the }\right. \\
\text { warehouse }>35,1 \text {, alarm } \\
\text { reliability) }\end{array}$ & $\begin{array}{l}\text { Variable activated when the } \\
\text { temperature in the warehouse } \\
\text { exceeds } 35^{\circ} \mathrm{C} \text {. }\end{array}$ \\
\hline $\begin{array}{l}\text { Maintaining the temperature in } \\
\text { the warehouse for flammables }\end{array}$ & $\begin{array}{l}\text { Equal : } \\
\text { Reliability of temperature } \\
\text { sensor }+ \text { quality of monitoring } \\
\text { of storage temperature }+ \\
\text { tripping of cooling system }\end{array}$ & $\begin{array}{l}\text { Maintaining the temperature is a } \\
\text { safety condition in the warehouse in } \\
\text { order to avoid the risk of fire or } \\
\text { explosion of the product containers. }\end{array}$ \\
\hline Quality of maintenance & $\begin{array}{l}\text { Equal : } \\
\text { Safety behavior of operators }+ \\
\text { relevance of maintenance } \\
\text { procedures }\end{array}$ & $\begin{array}{l}\text { Quality of maintenance influences } \\
\text { the functioning and reliability of } \\
\text { equipment. }\end{array}$ \\
\hline $\begin{array}{l}\text { Quality of monitoring of storage } \\
\text { temperature }\end{array}$ & $\begin{array}{l}\text { Depends on the behavior of } \\
\text { operators. }\end{array}$ & $\begin{array}{l}\text { Monitoring of storage temperature is } \\
\text { a safety condition in the warehouse. }\end{array}$ \\
\hline $\begin{array}{l}\text { Quality of safety control of } \\
\text { storage. }\end{array}$ & $\begin{array}{l}\text { Depends on the behavior of } \\
\text { operators and the relevance of }\end{array}$ & $\begin{array}{l}\text { Safety control makes it possible to } \\
\text { identify anomalies in the warehouse } \\
\text { (i.e. packaging, shelving). }\end{array}$ \\
\hline
\end{tabular}


checklists

Safety behavior of operators

Stress

Motivation

Safety conditions

Non-compliance situations

Improvement of safety

Correction of abnormalities

Information

Learning

Competence

Work environment

Training
State variable

INTEG (entry of behavior - exit of behavior)

State variable

INTEG (entry of stress - exit of stress)

State variable

INTEG (entry of motivation exit of motivation)

State variable

INTEG (entry of safety

conditions, 0.5 )

1/safety conditions

Depends on the presence of non-compliance situations

Depends on the results of the safety control of the storage

Depends on the analysis of noncompliance situations

Flow

State variable

INTEG (learning - exit of competence)

Graded on a qualitative scale bounded at 0 for the lower limit and 1 for the upper limit. For example, a low quality work environment equals 0 and a high quality environment has a value of 1

Graded on a qualitative scale bounded at 0 for the lower limit and 1 for the upper limit. For example a low intensity of training equals 0 and a high
Variable representing the level of operator behavior.

Variable representing the level of stress.

Variable representing the level of motivation.

Variable representing the state of safety conditions in the warehouse.

Depends on the state of safety conditions in the warehouse.

Improvement of safety is an important condition in the warehouse.

Abnormalities identified during the safety control are corrected.

Analysis of non-compliance situations is a source of information which improves the competence of operators.

Learning is done through training and through acquisition of additional knowledge during analysis of noncompliant situations.

Variable representing the level of competence.

Work environment influences the behavior of operators.

Training is a source of operator competence. 
intensity corresponds to a value of 1

Relevance of checklists

Relevance of maintenance procedure
Graded on a qualitative scale bounded at 0 for the lower limit and 1 for the upper limit. For example, a less relevant checklist equals 0 and a highly relevant one has a value of 1

Graded on a qualitative scale bounded at 0 for the lower limit and 1 for the upper limit. For example, a poor relevance of maintenance procedures equals 0 and high relevance corresponds to a value of 1
Checklists are used to safety control in warehouse storage.

Maintenance procedures are used during maintenance of safety devices.

Any operation simulation in system dynamics begins from a specified state of the system. Before running the simulation, the initial conditions for each state (or stock) variable must be defined. Every three years the industry concerned performs a safety audit. In this audit, a questionnaire is used to evaluate safety at the plant. The last audit was conducted at the end of 2009. To define the initial values of variables in the proposed model, we have relied on the results of this last audit. We developed an evaluation grid with a qualitative value scale (very low, low, medium, strong, very strong) which corresponds to the interval $[0 ; 0.25 ; 0.5 ; 0.75$; 1]. A value of 0 means very low and the value 1 means very strong.

Various sensitivity, or case studies, such as examining changes in the different variables, can be carried out using the model presented in Figure 5.

\subsection{Simulation and results (step 4)}

First of all, two case studies on the effect of training and work environment were carried out, to understand the impact of these safety variables. These factors were chosen following a request from the company. In each case study, we simulated the effects of two scenarios, an increase of $20 \%$, and a decrease of $20 \%$ of the factors in question: training and work environment. We chose a range of variation of $20 \%$ in order to follow the evolution of system safety and to test the sensibility of our model. This range of $20 \%$ was defined according to the most often range used in the literature (engineering, biology, mathematics, finance etc.), which is commonly between 10 and $20 \%$, in order to test the sensibility of the model.

Before showing the results of the simulation, the conditions of each case study are described in following table (table 2):

Table 2: Case study conditions.

Case Study Data Set Description




\begin{tabular}{lll}
\hline \multirow{2}{*}{$\begin{array}{l}\text { Case 1: Effect of } \\
\text { training }\end{array}$} & Current situation & 0.75 \\
\cline { 2 - 3 } & High training & Degree of increase: $+20 \%$ of the current situation \\
\cline { 2 - 3 } & Low training & Degree of decrease: $-20 \%$ of the current situation \\
\hline $\begin{array}{l}\text { Case 2: Effect of the } \\
\text { quality of the working } \\
\text { environment }\end{array}$ & Current situation & 0.75 \\
\cline { 2 - 3 } & Low relevance & Degree of increase: $+20 \%$ of the current situation \\
\cline { 2 - 3 } & High relevance & Degree of decrease: $-20 \%$ of the current situation \\
\hline $\begin{array}{l}\text { Time bounds for } \\
\text { model }\end{array}$ & $\begin{array}{l}\text { Initial time: } 0 \\
\text { Time step }\end{array}$ & Final time : 6 \\
\hline
\end{tabular}

The values given for the current situation correspond to the values of variables estimated in the 2009 safety audit. The duration of the simulation period is defined arbitrarily as six days.

Generally, in the storage unit studied, the prevention and reduction of risk situations provide safe working conditions. The safety level using the dataset from the current situation (or normal status) is presented in Figure 6. This figure shows the state of the variable "safety conditions" in the current situation, which is regarded here as the normal situation without any change of model variables.

\section{Figure 6: Simulation of current situation.}

First, the effects of training on safety are simulated (Figure 7). When the degree of training is increased, safety is little affected. The level of training in the system studied was qualified strong in 2009 (a value of 0.75). However, a high degree of training does not ensure a high degree of safety (the line with dashes and dots) compared to the current situation (the continuous line). On the other hand, a low level of training (untrained operators) can decrease safety (the dotted line) by a very significant amount. This reveals that managers should not decrease the level of training even if an increase seems to have no significant effect.

Figure 7: Effect of training on safety.

The effect of the quality of the working environment is shown in Figure 8.

Figure 8: Effect of the quality of the working environment on safety. 
As shown in Figure 8, deterioration in the working environment (reduction of quality) has a significant effect on safety (the dotted line), and a favorable work environment improves safety (the line with dashes and dots). These results can be explained through the impact that the working environment has on the behavior of operators, which is presented in Figure 9.

Figure 9: Effect of the quality of the working environment on the safety behavior of operators.

Figure 9 shows the effects of work environment quality on the behavior of operators. Line with dashes and dots presents the effect of a favorable work environment $(+20 \%$ of quality of work environment) on the behavior of operators. Dotted line presents the effect of an unfavorable work environment (-20\% of quality of work environment) on the behavior of operators. The causal diagram (Figure 4, particularly loops B1 and B2), shows that the variable "work environment" influences both behavioral factors "motivation" and "stress". When the work environment is favorable, motivation increases and stress decreases. Therefore, the motivation of operators positively influences their behavior. Operators, through their behavior affect the quality and success of all operations and actions relating to risk control in the system. The tree shown in Figure 10 illustrates the relationship between the safety behavior of operators and the various actions and measures relating to risk control that define safety conditions in the chemical warehouse.

This tree shows the importance of operators' behavior as the major challenge in system safety, and explains the effect of the quality of the working environment on safety shown in Figure 8. Operators through their behavior, influence the quality and success of all safety actions in the system. Indeed, the operators perform the following activities:

- Correction of abnormalities to avoid a potential accident.

- Monitoring the storage temperature which allows maintaining the temperature in the warehouse.

- Maintenance which influence the reliability of safety devices

- Control of storage which allows correcting any defect in storage.

All of these actions are safety measures in the system and operators' behavior is considered as the major challenge in system safety.

The causal diagram presented in the figure 4 shows the influence of work environment on the behavior of operators. A favorable work environment positively influences the behavior of operators, and an unfavorable work environment negatively influences operators. Always in the causal diagram, poor operator performance during a maintenance operation will generate poor quality equipment maintenance, and therefore failure of the temperature sensor and a dysfunctional alarm. So, any change in the quality of the work environment has an effect on the behavior of operators and consequently on the safety of system. However, adequate 
control of storage enables abnormalities to be corrected and maintains the system in a safe condition.

Figure 10: Use tree showing the variable "safety behavior of operators".

All of these various actions and factors that define the safety conditions in the chemical warehouse are illustrated in the tree shown in Figure 11. This tree is a graphical representation giving a full description of the various feedback loops shown in Figure 4 and highlights the causal interdependencies between safety conditions.

Figure 11: Cause tree showing the variable "safety conditions".

The results of these case study simulations on the effects of training and the work environment can be used to understand the impact of these variables on safety. The simulation results show that a low level of training (untrained operators) can decrease safety (the dotted line, Fig 7) by a very significant amount and may result in low performance for an overhaul period. The lesson learning from this analysis is that the managers should maintain the high level of operator training even if an increase seems to have no significant effect. It means that, if managers organize two or three training per year, they must maintain this number because a reduction in training has an impact on safety. In fact, training is an important factor that can improve operator skills and update their knowledge. As sown in Fig 4, learning through training has a positive influence on safety behavior of operators and increases the competence of operators (loop B7).

The simulations results also show that deterioration in the working environment has a significant effect on safety and a favorable work environment improves safety (Fig 8). This relationship between the work environment and safety is shown in causal diagram through the impact that the working environment has on the behavior of operators (Fig 4). A favorable work environment has a positive effect on the motivation of operators, and a negative effect on stress (loop B1). Loop B2 shows that the motivation of operators has a positive influence on their safety behavior. Stress has a negative impact on their behavior. The lesson learning from this analysis is that the managers should maintain the quality of working conditions that directly and strongly affect the safety behavior of operators.

All of these results also show the importance of operators' behavior as the major challenge in system safety. In fact, Operators through their behavior, influence the quality and success of all safety actions in the system. A more detailed study of operators' behavior also seems very important to monitor and control the human behavior in a complex safety system like that of the safety conditions in the storage unit of chemicals. 
The results of this analysis are encouraging and serve as a good demonstration of the potential use of proposed modeling to improve our understanding of the safety conditions of complex systems and to use it as tools for continuous improvement.

\section{Conclusion}

This paper describes the use of the system dynamics methodology to support decisions related to the improvement of industrial safety and the implementation of managerial tools involving organizational, technical and human factors. This model takes into account two aspects: the dynamic aspect, by formalizing the causal interactions between system components, and the time aspect, showing the behavior of system components over time. The use of system dynamics simulation is particularly innovative in the context of risk management in the process industries according to the classical methodologies applied in the safety reports: these classical methodologies do not take into account the temporal dimension and do not simulate the behavior of a socio-technical system that supposes to integrate in the model the technical, organizational and human dimensions.

This model can be applied to review industrial safety in terms of organization. The formalization of such model represents a communication mean, even a training tool, for policy makers and operators. This model gives information about safety through simulation of normal and abnormal conditions in order to check and improve the performance of the safety means implemented in the plant. Simulation results give to the managers insights in order to support their decisions in terms of safety. When considering situations where managers are periodically changed, managers can coherently execute their policies using this model by implementing managerial tools involving organizational, technical and human factors. The application of this approach in the context of industrial system provides a dynamic analysis of safety. This model can be generalized and applied to other industrial sectors which can be more complex and for which risk analysis meet difficulties.

The limits of this approach are essentially linked to the degree of complexity the expert seeks to investigate, because of the time it takes to develop the model, to define the variables, to create the simulation and to interpret the results.

\section{References}

Akkermans, H. A., 2001. Systems approach to facilitating inter-organizational network development. System Dynamics Review 17(3), pp. 40-57.

Aracil, J., 1984. Introduction à la dynamique des systèmes; translated by M.Ossandon-Lyon: presse universitaire de Lyon, pp. 414.

Boucher, X., Burlat. P., 2003. Vers l'intégration des compétences dans le pilotage des performances de l'entreprise. JESA 37 (3), pp. 363-390. 
Bouloiz, H., Garbolino, E., Tkiouat, M., 2010. Contribution of a systemic modeling approach applied to support risk analysis of a storage unit of chemical products in Morocco. Journal of Loss Prevention in the Process Industries 23, pp. 312-322.

Cooke, L.D., 2002. A System Dynamics Analysis of the Westray Mine Disaster.

Forrester, J.W., 1961. Industrial Dynamics, Cambridge: MIT Press, pp.464.

Garbolino, E., Chery, J.P., Guarnieri. F., 2010a. Dynamic Systems Modeling to improve risk analysis in the context of Seveso industries. Chemical Engineering Transactions 17, pp. 373-378.

Garbolino, E., Chery J.P., Guarnieri, F., 2010b. Dynamic Risk Assessment in the process industries: proposal of a methodology based on the System Dynamics approach. ESREL, 5-9 September, Rhodes, Greece.

Garbolino, E., Chery, J.P., Guarnieri, F., 2009. Systems Dynamics modeling to improve risk analysis in the context of Seveso industries. AIDIC Conference Series, Selected Papers 9, pp. 149-158.

Garcia, J.M., 2006. Theory and practical exercises of system dynamics. Barcelona, Spain: Universitat Politecnica De Catalunya.

Giambiasi, N., Frydman, C., Seck. M., 2005. Modélisation et simulation du comportement humain avec le formalisme devs. In Actes de 6ème Conférence Francophone de Modélisation et Simulation (MOSIM'06), Maroc.

Graham, A.K., Ariza, A., 2003. Dynamic, hard and strategic questions: using optimization to answer a marketing resource allocation question, System Dynamics Review 19(1), pp. 27-46.

Groeneweg, J., Lancioni, G.E., Metaal, N., 2002. Tripod: Managing organizational components of business upsets. Safety and Reliability, pp. 707-712.

Harvey, S., Courcy, F., Petit, A., Hudon, J., Teed, M., Loiselle, O., Morin, A., 2006. Interventions organisationnelles et santé psychologique au travail : une synthèse des approches au niveau international. Rapport, IRSST, Montreal.

Hjorth, P., Bagheri, A., 2006. Monitoring for suitable development: a systemic framework. International Journal of Sustainable Development 8, pp. 280-301.

Hollnagel, E., 1998. Cognitive reliability and error analysis method. Elsevier Science, pp.1-287. Ltd., ISBN 0-08-0428487.

Hollnagel, E., 2004. Barrier analysis and accident prevention. Aldershot, UK, Ashgate,

Jasanoff, S., 1994. Learning from disaster: Risk management after Bhopal. Philadelphia: University of Pennsylvania Press, pp.361.

Jones, C., 2005. Behavioral theory in simulation: Ambiguous results from simple relationships. In Proceedings the 23rd International Conference of the System Dynamics Society, USA.

Kalantarnia, M., Khan, F., Hawboldt, K., 2009. Dynamic risk assessment using failure assessment and Bayesian theory. Journal of Loss Prevention in the Process Industries, 22, pp. 600-606.

Karsky, M., Donnadieu, G., 1990. The Dynamic of Behavior and Motivation. Proceeding of the International System Conference: Boston.

Khan, F.I., Abbasi, S.A., 1998. Techniques and methodologies for risk analysis in chemical process industries. Journal of Loss Prevention in the Process Industries, pp.261-277.

Koelling, P., Schwandt M.J., 2005. Health systems: a dynamic system - benefits from system dynamics. Winter Simulation Conference, December 4-7, Orlando, pp. 1321-1327.

Kyung, M.K., Moosung, J.A., 2004. Quantitative assessment of LCOs for operations using system dynamics. Journal of Reliability Engineering and System Safety 87(2), pp. 211-222 
Le Coze J.C., Vince, A.S., Salvi, O., Prats, F., Plot, E., 2002. Development of the ATOS concept analysis of technical and organisational safety. Lyon. Proceedings of the ESREL Conference, pp. 19-21.

Leveson, N., 2004. A New Accident Model for Engineering Safety Systems. Safety Science 42 (4), pp. $237-270$.

Leveson, N., Daouk, M., Dulac, N., Marais, K., 2003. Applying STAMP in Accident analysis. Massachusetts Institute of Technology.

Meadows, D.H, Meadows, D.L., Randers, J., Behrens, W.W., 1972. The Limits to Growth. New York: Signet.

Milling, P.M., 2002. Understanding and managing innovation processes. Mannheim University, Germany.

Nicolet-Monnier, M., 1996. Integrated regional risk assessment: the situation in Switzerland. International Journal of Environment and Pollution 6(4-6), pp.441-461.

Paulré, B., 1992. Systémique, Théorie et applications, Technique et documentation - Lavoisier, Paris.

Paté-Cornell, M.E., 1999. A Post Mortem Analysis of the Piper Alpha Accident: Technical and Organizational Factors. Risk Analysis 13(2), pp. 215-232.

Paté-Cornell, M.E., Murphy, D.M., 1996. Human and management factors in probabilistic risk analysis: The SAM approach and observations from recent applications. Reliability Engineering and System Safety. Elsevier Science Ltd 53(2), pp. 115-126.

Perrow, C., 1994. The limits of safety: The Enhancement of a Theory of Accidents. Journal of Contingencies and Crisis Management 2 (4).

Provitolo, D., 2005. Risque Urbain, catastrophe et villes méditteranéennes. Thèse de doctorat. Université Nice-Sophia Antipolis, pp. 365.

Rehan, R., Nehdi, M., Simonovic, S.P., 2005. Policy making for greening the concrete industry in Canada: a systems thinking approach. Canadian Journal of Civil Engineering 32(1), pp. 99-113.

Reason, J., 1997. Managing the risks of Organizational Accidents, Ashgate;.

Repenning, N.A., 2000. Simulation-Based Approach to Understanding the Dynamics of Innovation Implementation. Organization Science 13 (2), pp. 109-127.

Roberts, K.H., 1990. Some characteristics of one type of high reliability organization. Organization science 1(2), pp. 160-176.

Rogers, R.L., 2000. Methodology for the risk assessment of unit operations and equipment for use in potentially explosive atmospheres. EU RASE Project no SMT4eCT97. Library Area SAFETYNET, Inburex GmbH Hamm, Allemagne;.

Rudolph, J., Repenning, N., 2002. Disaster Dynamics: Understanding the Role of Stress and Interruptions in Organizational Collapse, Administrative Science Quarterly 47, pp. 1-30.

Ryan, R., Deci, E., 2000. Intrinsic and extrinsic motivations: Classic definitions and new directions. Contemporary Educational Psychology 25, pp. 54-67.

Salge, M., Milling, M.P., 2006. Who is to blame, the operator or the designer? Two stages of human failure in the Chernobyl accident. System Dynamics Review 22 (2), pp. 89-112.

Sterman, J.D., 2000. Business Dynamics: Systems Thinking and Modeling for a Complex World. McGraw-Hill, NY, USA. 
Tauheed, L., Wray, L.R., 2006. System Dynamics of Interest Rate Effects on Aggregate Demand. in L. Randall Wray and Mathew Forstater (eds.) Money, Financial Instability, and Stabilization Policy. Cheltenham: Edward Elgar.

Thompson, J.P., 1999. Consulting Approaches with System Dynamics: Three Case Studies, System Dynamics Review 15(1), pp. 71-96.

Ventana System, 1999. VENSIM reference manual version 4.

Wiener, N., 1948. Cybernetics or Control and Communication in the Animal and the Machine. 


\section{Index of Tables and Figures}

Table 1: Definition and role of all variables used to model the safety conditions in the warehouse for flammables.

Table 2: Case study conditions.

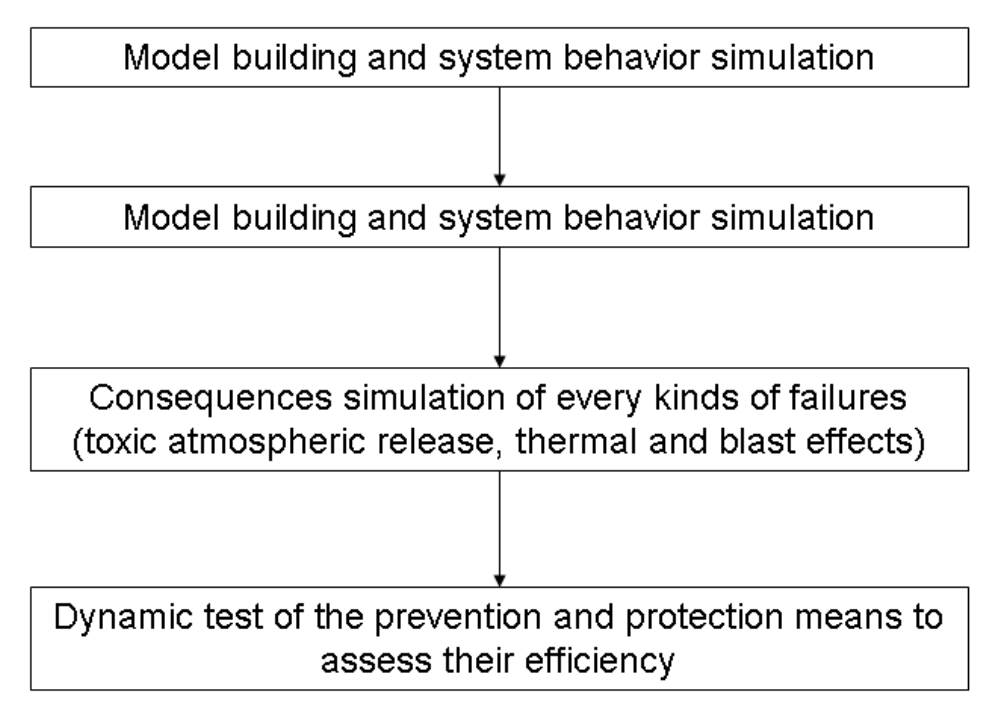

Figure 1: Description of the dynamic risk analysis methodology (Garbolino et al., 2009, 2010a and 2010b).

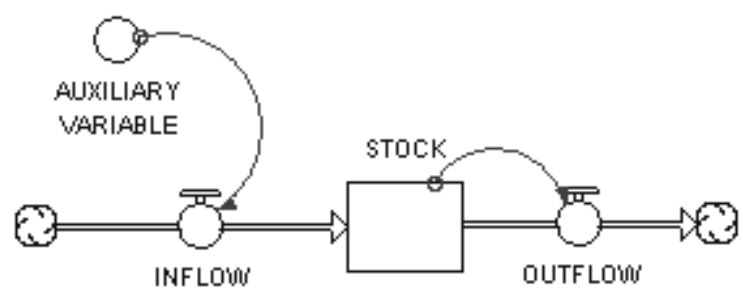

Figure 2: Schematic of a system dynamics model using the stock, flow and auxiliary variables proposed by Forrester (Forrester, 1961). 


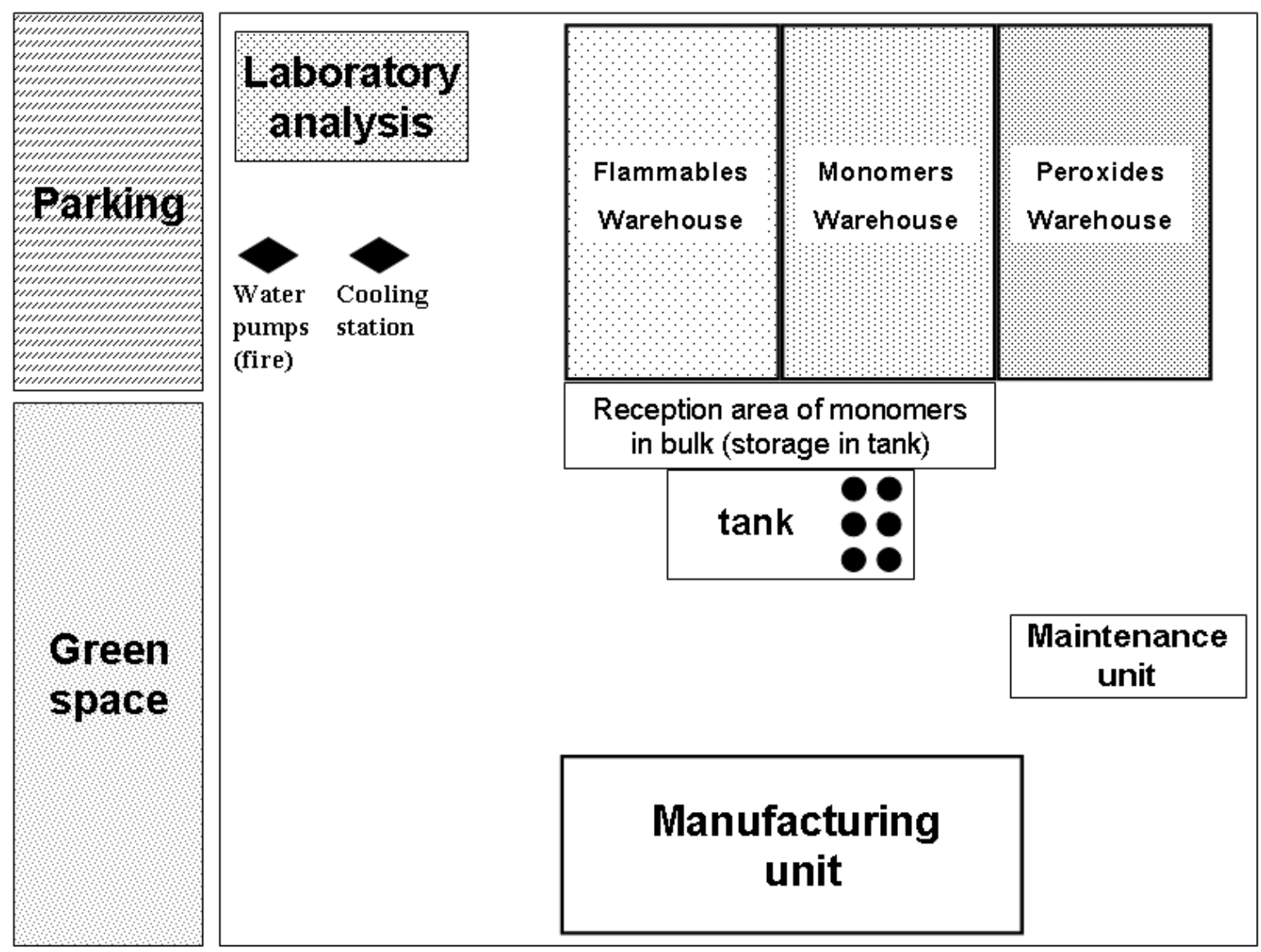

Figure 3: Configuration of the industrial site. 


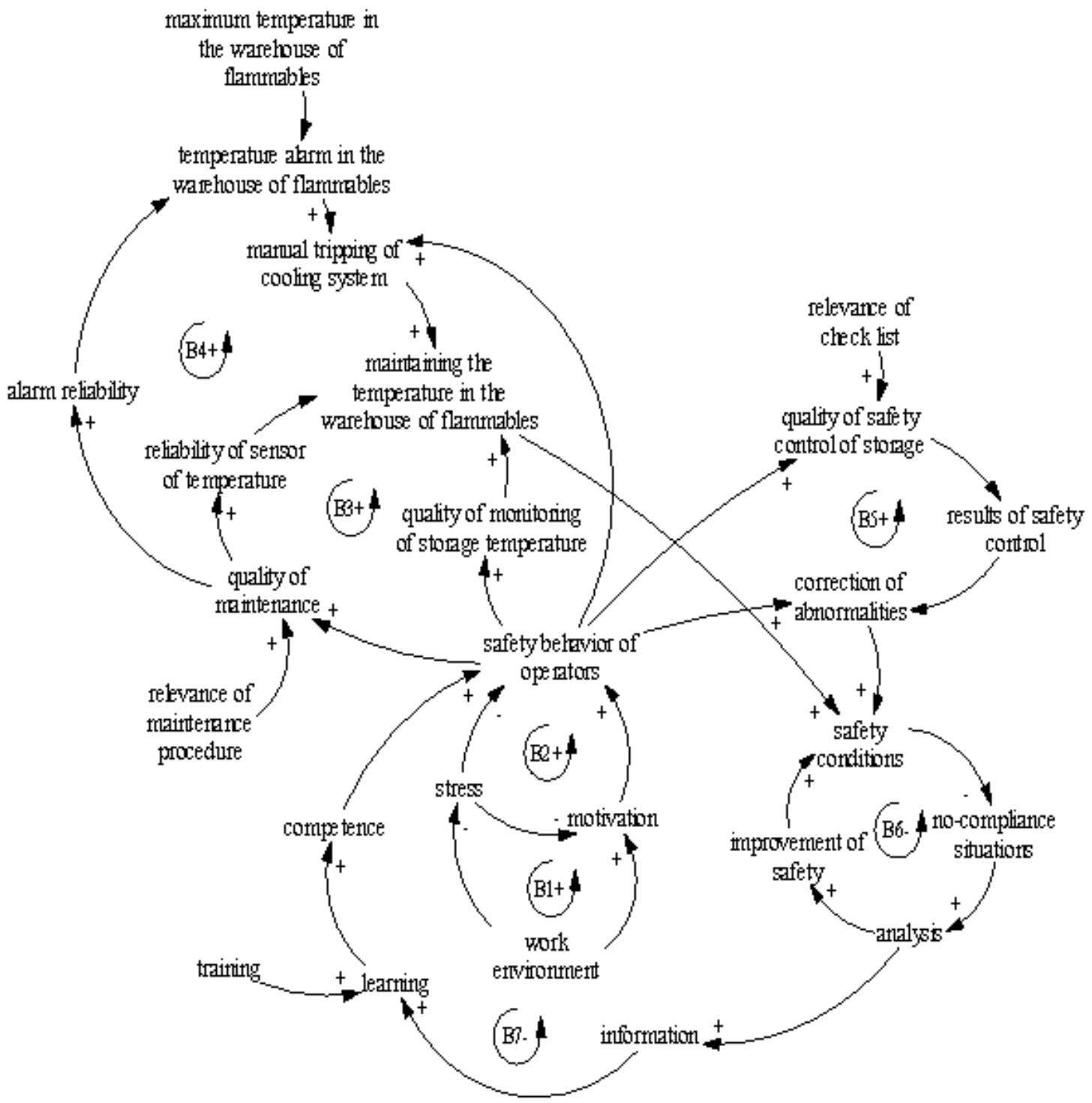

Figure 4: Causal diagram showing safety conditions in the chemical storage unit. 


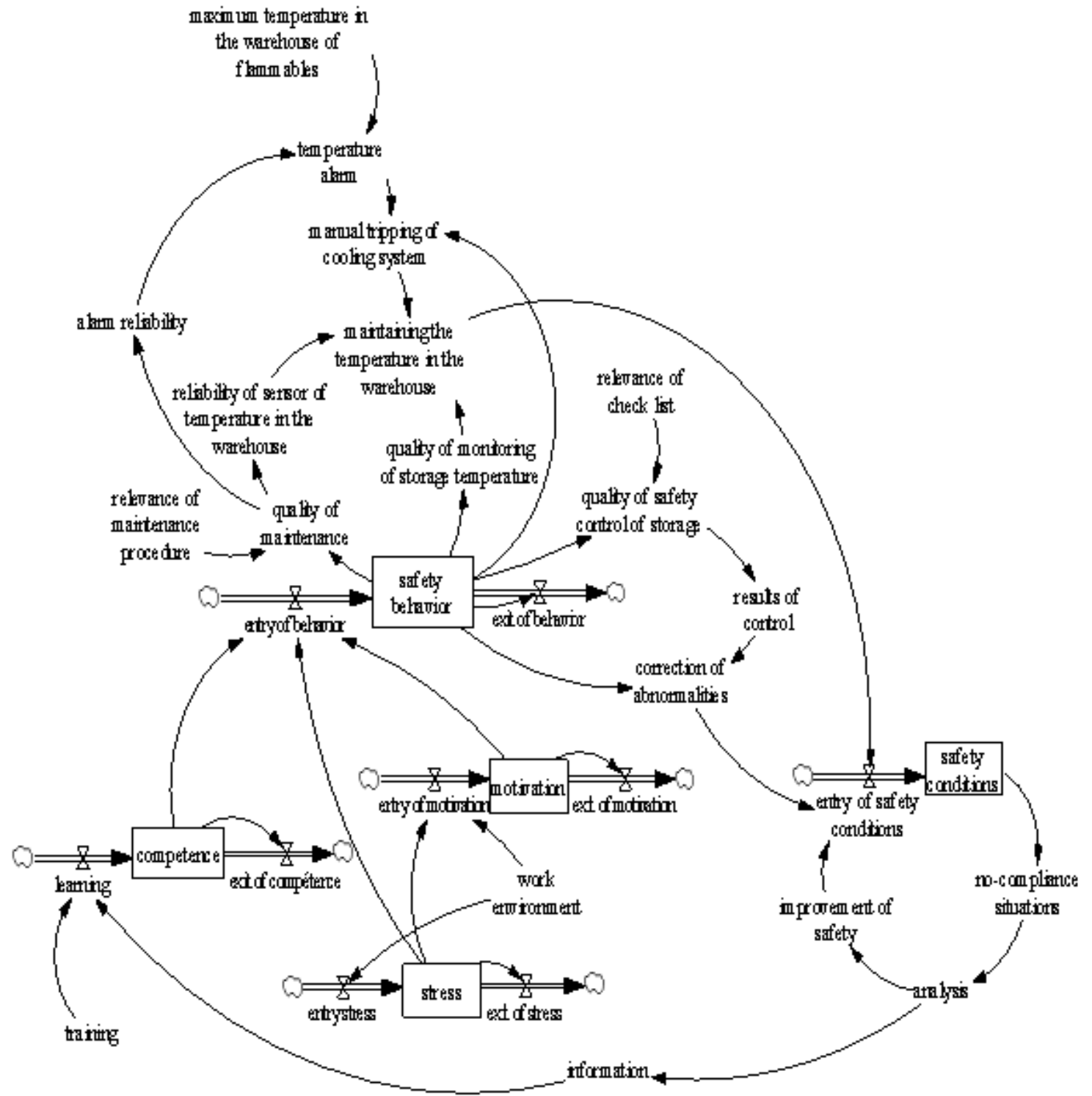

Figure 5: Stock and flow diagram showing the safety conditions in the chemical storage unit. 
Safety conditions

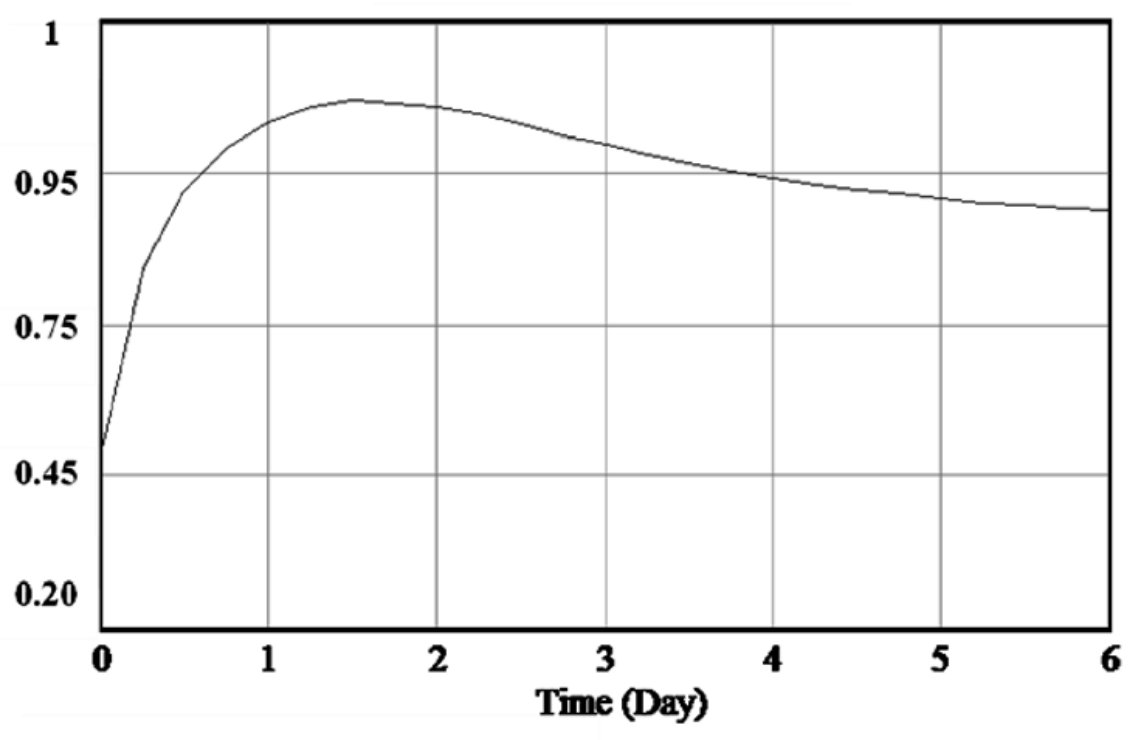

Safety conditions : current

Figure 6: Simulation of current situation.

Safety conditions

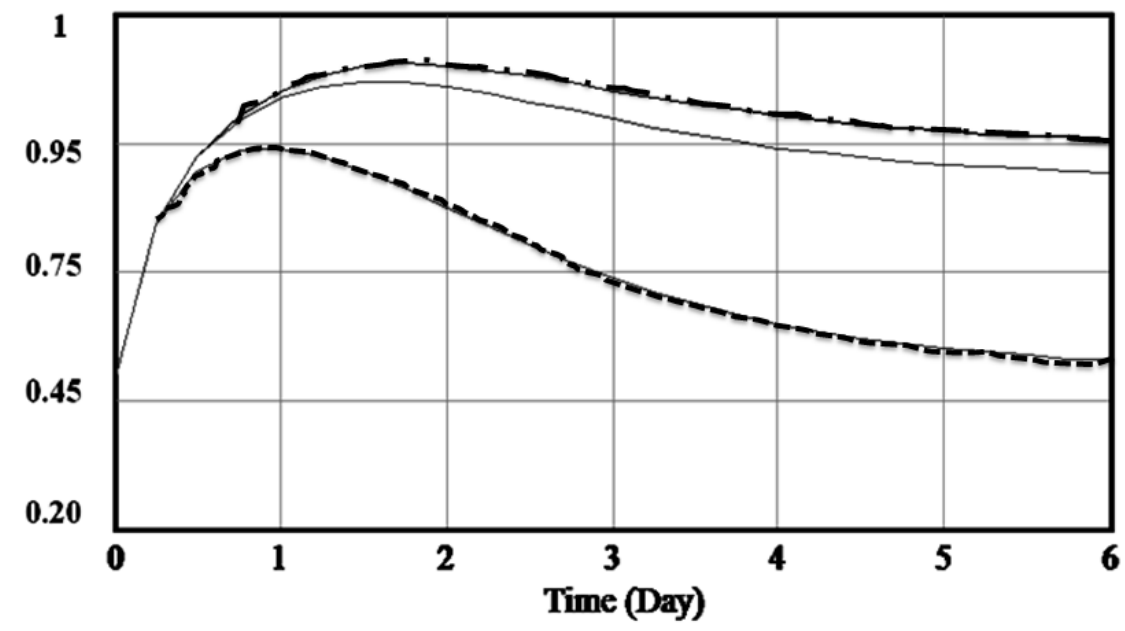

Safety conditions: current Safety conditions : $-20 \%$ training -Safety conditions : $+20 \%$ training _ _ . _ . _ _ _ . -

Figure 7: Effect of training on safety. 
Safety conditions

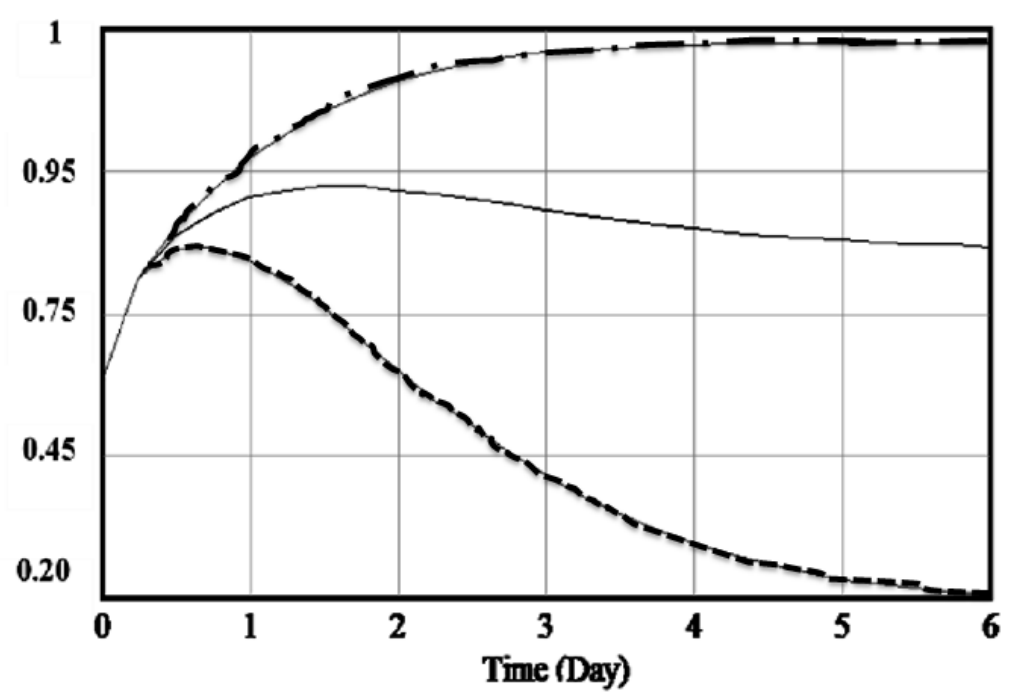

Safety conditions : $+20 \%$ of quality of work environment safety conditions : $-20 \%$ of quality of work environment Safety conditions : current

Figure 8: Effect of the quality of the working environment on safety.

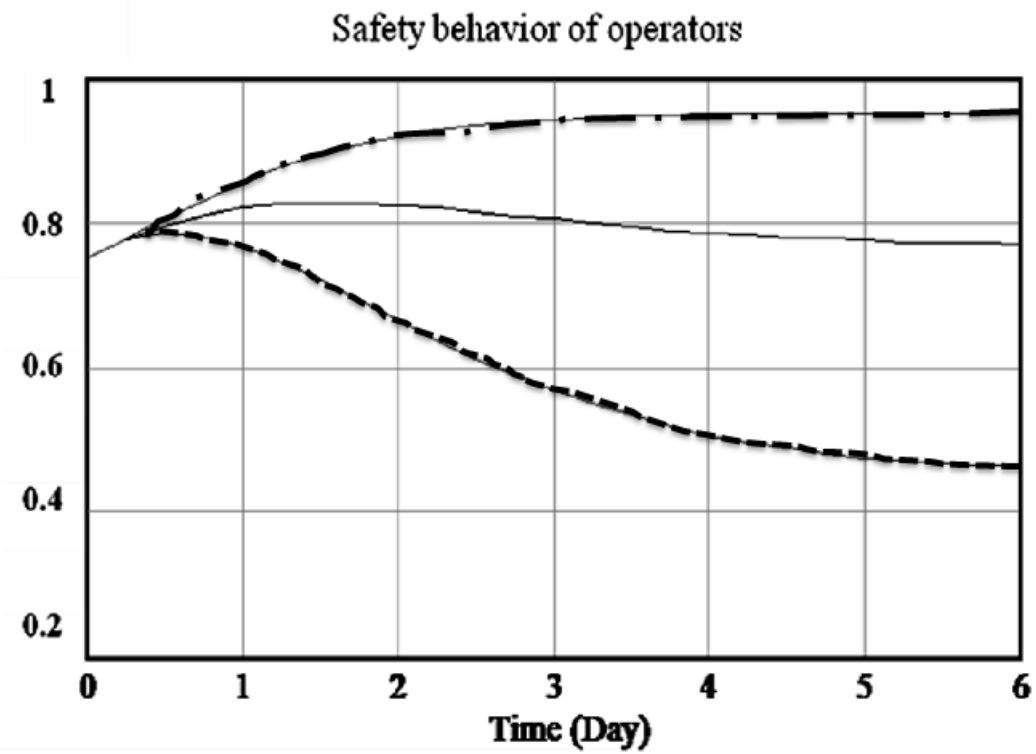

Safety conditions : $+20 \%$ of quality of work environment safety conditions : - $20 \%$ of quality of work environment

Safety conditions : current

Figure 9: Effect of the quality of the working environment on the safety behavior of operators. 


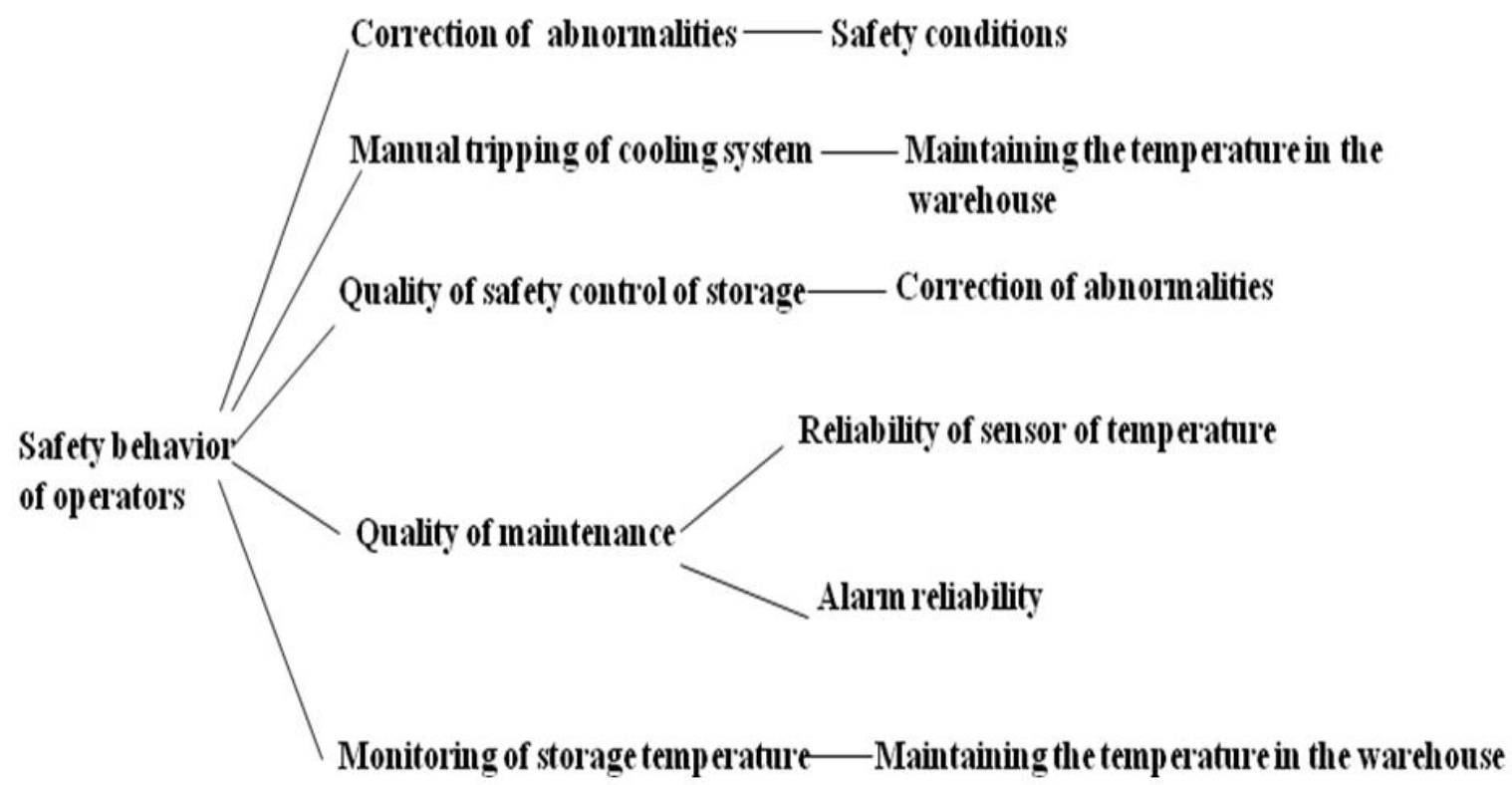

Figure 10: Use tree showing the variable "safety behavior of operators".

Safety behavior of operators - Quality of saf ety control of storage

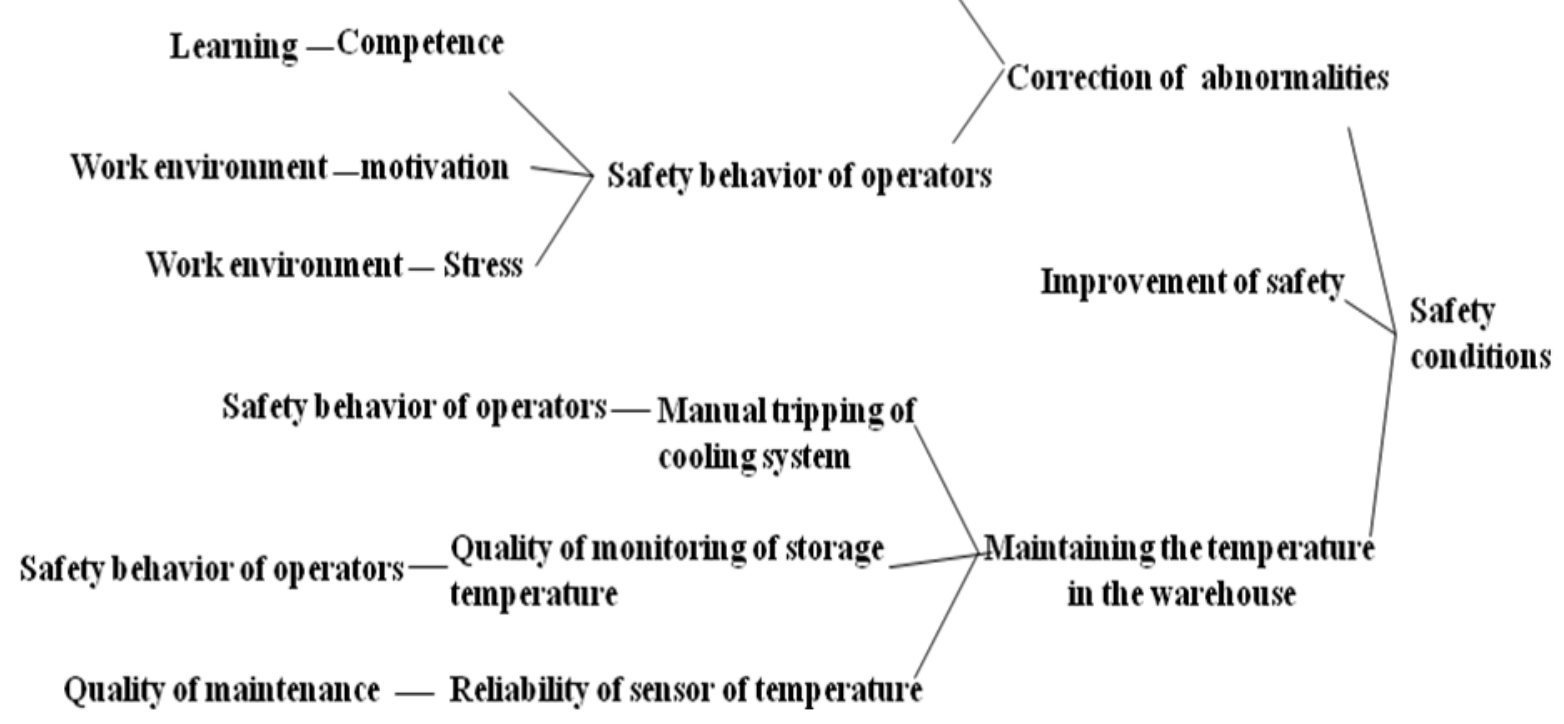

Figure 11: Cause tree showing the variable "safety conditions". 